\title{
The many faces of diabetes. Is there a need for re-classification? A narrative review
}

\author{
Nasser Sakran ${ }^{1,2}$, Yitka Graham, ${ }^{3,4}$, Tadeja Pintar ${ }^{5}$, Wah Yang ${ }^{6}$, Radwan Kassir $^{7}$, Edith M. Willigendael ${ }^{8}$, Rishi Singhal ${ }^{9}$, \\ Zoë E. Kooreman ${ }^{10}$, Dharmanand Ramnarain ${ }^{11}$, Kamal Mahawar ${ }^{3,12}$, Chetan Parmar ${ }^{13}$, Brijesh Madhok ${ }^{14}$ and \\ Sjaak Pouwels ${ }^{11,15^{*}}$ (D)
}

\begin{abstract}
The alarming rise in the worldwide prevalence of obesity and associated type 2 diabetes mellitus (T2DM) have reached epidemic portions. Diabetes in its many forms and T2DM have different physiological backgrounds and are difficult to classify. Bariatric surgery (BS) is considered the most effective treatment for obesity in terms of weight loss and comorbidity resolution, improves diabetes, and has been proven superior to medical management for the treatment of diabetes. The term metabolic surgery (MS) describes bariatric surgical procedures used primarily to treat T2DM and related metabolic conditions. MS is the most effective means of obtaining substantial and durable weight loss in individuals with obesity. Originally, BS was used as an alternative weight-loss therapy for patients with severe obesity, but clinical data revealed its metabolic benefits in patients with T2DM. MS is more effective than lifestyle or medical management in achieving glycaemic control, sustained weight loss, and reducing diabetes comorbidities. New guidelines for T2DM expand the use of MS to patients with a lower body mass index.

Evidence has shown that endocrine changes resulting from BS translate into metabolic benefits that improve the comorbid conditions associated with obesity, such as hypertension, dyslipidemia, and T2DM. Other changes include bacterial flora rearrangement, bile acids secretion, and adipose tissue effect.

This review aims to examine the physiological mechanisms in diabetes, risks for complications, the effects of bariatric and metabolic surgery and will shed light on whether diabetes should be reclassified.
\end{abstract}

Keywords: Diabetes mellitus, Bariatric surgery, Antidiabetic drugs, Gastrointestinal hormones, Metabolic surgery, Classification

\section{Background}

As far back as 1550, Before Common Era (BCE), history documents words on an Egyptian papyrus referring to an illness in which patients lost weight and urinated frequently. Over 1000 years later, Appolonius was credited with being the first to use the word 'diabetes,' with Galen suggesting diabetes is kidney disease [1]. In 5

\footnotetext{
* Correspondence: sjaakpwls@gmail.com

${ }^{11}$ Department of Intensive Care Medicine, Elisabeth-Tweesteden Hospital, Tilburg, The Netherlands

${ }^{15}$ Department of Intensive Care Medicine, ETZ Elisabeth, Hilvarenbeekseweg 60, P.O. Box 90151, 5000 LC Tilburg, The Netherlands

Full list of author information is available at the end of the article
}

Common Era (CE), Sushruta, the Indian surgeon, noted the sweetness of the urine, it is sticky feeling, and the ability to attract ants, and noted that diabetes tended to afflict the higher castes and related the condition to excessive consumption of rice, cereal, and sweet foods [2]. In the late 1700s, Dobson discovered that the sweet taste in the urine of people with diabetes is due to excess sugar in both urine and blood. His observations of patients lead to future differentiation of Type I and Type 2 Diabetes (T2DM) [3]. In 1889, Mering and Minkowski discovered that removing the pancreas from dogs led to developing diabetes and death helped scientists understand the association with pancreas and blood sugar

(c) The Author(s). 2021 Open Access This article is licensed under a Creative Commons Attribution 4.0 International License, which permits use, sharing, adaptation, distribution and reproduction in any medium or format, as long as you give appropriate credit to the original author(s) and the source, provide a link to the Creative Commons licence, and indicate if changes were made. The images or other third party material in this article are included in the article's Creative Commons licence, unless indicated otherwise in a credit line to the material. If material is not included in the article's Creative Commons licence and your intended use is not permitted by statutory regulation or exceeds the permitted use, you will need to obtain permission directly from the copyright holder. To view a copy of this licence, visit http://creativecommons.org/licenses/by/4.0/ The Creative Commons Public Domain Dedication waiver (http://creativecommons.org/publicdomain/zero/1.0/) applies to the data made available in this article, unless otherwise stated in a credit line to the data. 
levels. Soon after, Sharpey-Schafer posited that diabetes developed due to a lack of a substance in the pancreas, which he called insulin [4]. The discovery of insulin by Banting and Best in 1921 heralded a breakthrough for diabetes treatment, with the first human to receive insulin treatment in 1922. In 1936, Himsworth differentiated between Type 1 and T2DM, suggesting insulin resistance rather than deficiency [4]. Rates of diabetes declined in Germany and other European countries during WWI and World War II, attributed to food shortages; this was not apparent in Japan and North America, where there was no rationing [5]. Table 1 gives an overview of the pivotal historical events in recognizing diabetes as a disease and the development of early diagnostic and therapeutic measures.

With the rise of bariatric and metabolic surgery (BMS), new surgical and physiological challenges became apparent. Evidence has shown that endocrine changes resulting from surgery translate into metabolic benefits that improve the comorbid conditions associated with obesity, such as hypertension, dyslipidemia, and T2DM. Other changes include bacterial flora rearrangement, bile acids secretion, and adipose tissue

Table $1 \mathrm{~A}$ brief history of diabetes mellitus research and development [6-8]

\begin{tabular}{ll}
\hline Time & Development \\
\hline 550 Common & Variations of diets \\
Era (CE) & Bleeding, emetics and narcotics \\
1921 & Discovery of insulin \\
1923 & Commercial animal insulin available \\
1936 & Introduction of long-acting insulin \\
1941 & Urine-testing tablets for sugar available \\
1949 & Syringe drivers for insulin \\
1961 & Glucagon available for hypoglycemia \\
1971 & The first blood glucose meter developed \\
1972 & Metformin approved for use in Canada \\
1983 & Recombinant insulin developed \\
1995 & First Alpha-glucosidase inhibitor (AGI) Acarbose \\
1996 & First Thiazolidinedionederivate (TZD) Troglitazone \\
1997 & First Meglitinide Repaglinide \\
$\mathbf{2 0 0 5}$ & First Amylin agonist pramlintide \\
& First Glucagon-Like Peptide 1(GLP-1) receptor \\
$\mathbf{2 0 0 6}$ & agonist (exenatide) \\
$\mathbf{2 0 0 8}$ & First Dipeptidyl peptidase-4 (DPP-4) inhibitor \\
& (sitagliptin) \\
& Colesevelam approved for diabetes \\
& Bromocriptine approved for diabetes \\
& First Sodium Glucose Transporter-2 (SGLT-2) \\
inhibitor (canagliflozin)
\end{tabular}

effect. This review aims to examine the physiological mechanisms in diabetes, risks for complications, the effects of BMS and will shed light on whether diabetes should be reclassified.

\section{Pathophysiology and definition of diabetes in general}

The pathophysiology and definitions of diabetes are complex, and with hormonal discoveries, it gets even more complex in the last few years. In general, diabetes can be classified into the following categories [9, 10]: Type 1 Diabetes Mellitus (T1DM) (due to beta cell destruction, nearly always insulin deficient); Type 2 diabetes (T2DM) (due to a progressive insulin secretory defect on the background of insulin resistance). Within this spectrum there are several types: Gestational diabetes mellitus (GDM) (diabetes diagnosed in the second or third trimester of pregnancy that is not overt diabetes) and specific types of diabetes due to other causes, e.g., monogenic diabetes syndromes (such as neonatal diabetes and maturity-onset diabetes of the young [MODY]), diseases of the exocrine pancreas (such as cystic fibrosis), and drug- or chemical-induced diabetes (such as in the treatment of HIV/AIDS or after organ transplantation) $[9,10]$.

T1DM is considered a chronic autoimmune disorder caused by the progressive T-cell mediated destruction of pancreatic $\beta$-cells that produce insulin. Apart from the decline in $\beta$-cell mass due to this phenomenon, the gradual loss of glucose sensitivity of the $\beta$-cells contributes to the deficient levels of insulin, causing hyperglycemia $[6,9,11]$. T1DM frequently occurs in childhood and has a peak incidence at 10-14 years [12]. The pathogenesis of T1DM consists of a complex interplay between a predisposing genetic risk and environmental factors and triggers [13]. The primary risk factor for $\beta$ cells auto-immunity is genetic, mainly in individuals with one or both human leukocyte antigen (HLA) class 2 haplotypes involved in antigen presentation. Studies in first-degree relatives show that the presence of two or more $\beta$-cell targeting autoantibodies is a predictor for T1DM. The disease progression depends on the age of antibody detection, amount of antibodies; its specificity, and antibody titer $[6,9,10]$. Environmental factors that trigger auto-immunity are infections, dietary factors, psychosocial stress, and altered intestinal microbiome composition [14].

Altered gut microbiome trigger host metabolism via modulating the production of short chain fatty acids (SCFA) in T2DM and is related to insulin sensitivity, lipid and glucose metabolism. Intestinal dysbiosis is related to increased intestinal permeability that allows translocation of bacterial lipopolysaccharide into systemic circulation. As a consequence, liver fat accomulation progresively 
increase fibrosis, weight gain and progression of T2DM. Furthermore, intestinal microbiome may have suppresive effect on fasting-induced adipocyte factor which acts as an inhibitor to circuating lipoprotein lypase and this consequently increas triacylglycerol (TAG) storage in periferal tissues. Microbiota also, is responsable for metabolism of liver derivated primary bile acids into.

secondary bile acids are reabsorbed into systemic circulation and take over the function of signaling molecules (interplayed via farnesoid receptor X, FXR) included in glucose homeostasis regulation [14].

Over $90 \%$ of all diabetes are cases of T2DM, a chronic metabolic disease characterized by a relative insulin deficiency due to the combination of deficient secretion, tissue insulin resistance, and inadequate compensatory mechanisms. In a later stage, unsustainable serum glucose levels can lead to diabetic complications [15]. In an excessive nutritional state, hyperglycemia and hyperlipidemia can ultimately cause inflammation and stress on the $\beta$-cells, leading to dysfunction and further stage atrophy. At diagnosis, up to $50 \%$, $\beta$-cell loss is described. Insulin resistance causes an increased glucose production in the liver and reduces peripheral glucose uptake in the muscle, liver, and adipose tissue [16]. Hypertrophic adipose tissue in obesity stimulates insulin resistance through increased circulation of pro-inflammatory and free fatty acid release. The chronic mild inflammatory state represents a key part of the pathogenesis of T2DM [15].

\section{Complications of diabetes mellitus}

Diabetes is a disease that is strongly associated with both macrovascular complications, including ischemic heart disease, cerebrovascular disease, and peripheral vascular disease, and microvascular complications, including nephropathy, retinopathy, and neuropathy. This results in organ and tissue damage in approximately one-third to one-half of patients with diabetes [17]. Diabetesassociated vascular alterations include anatomic, structural, and functional changes leading to multi-organ dysfunction [18].

The relationship between poor glycaemic control and microvascular and macrovascular complications was established in the prospective Diabetes Control and Complications Trial (DCCT) [19-21]. The cause for the increased morbidity and mortality is a direct result of diabetes and is a consequence of the combination of macrovascular (atherosclerosis) and microvascular disease. The importance of tight glycemic control for protection against macrovascular disease in diabetes has also been established in the DCCT/Epidemiology of Diabetes Interventions and Complications (EDIC) study for T1DM [22, 23].

For patients with T2DM, only limited clinical trial data have shown a macrovascular benefit with intensive therapy [24]. Selecting appropriate target glycated hemoglobin (A1C) should be individualized based upon individual comorbidities and functional status. The results of the Action to Control Cardiovascular Risk in Diabetes (ACCORD) trial suggest that a target A1C of 7.0 to $7.9 \%$ may be safer for patients with longstanding T2DM and who are at high risk for cardiovascular disease (CVD) than a target A1C of less than 6.0\% [25]. With respect to patients with newly diagnosed T2DM, the literature shows a long-term improvement in reducing the risk of myocardial infarction, diabetes-related death, and overall death after an intensive control (A1C $7 \%)$ [26, 27]. Improved glycaemic control lowers the risk of microvascular complications in patients with type 2 diabetes [24, 25, 28-31]. However, the absolute risk for microvascular complications and the incremental benefit of intensively lowering $\mathrm{A} 1 \mathrm{C}$ must be balanced against the diminishing returns and the heightened risk of hypoglycemia at $\mathrm{A} 1 \mathrm{C}$ levels less than $6.5 \%$. The A1C goal should be set somewhat higher $(<8 \%$ or higher) for patients with a history of severe hypoglycemia, patients with limited life expectancy, very young children or older adults, and individuals with advanced complications or comorbid conditions [7, 32].

\section{Macrovascular complications}

Cardiovascular disease (CVD) causes up to $65 \%$ of all deaths in people with diabetes [33]. For patients with T2DM, CVD is the leading cause (70\%) of death [33]. Diabetes gives a 4-fold-greater risk for CVD's compared to patients without diabetes, corrected for risk factors like age, obesity, tobacco use, dyslipidemia, and hypertension [34, 35]. These risk factors are common in diabetes, but data suggest that diabetes is an independent risk factor for CVD.

Patients with diabetes, especially T2DM, have many traditional risk factors for CVD, including central obesity, dyslipidemia, and hypertension [36]. In general this combination is referred to as "metabolic syndrome" (central adiposity, dyslipidemia, hyperglycemia, and hypertension) [37]. Along with the independent risk factor of diabetes, these factors can act both independently and cumulatively over time to significantly increase the risk for CVD. The combination of hyperglycemia, insulin resistance, dyslipidemia, hypertension, and chronic inflammation can injure the vascular endothelium, leading to macrovasculopathy and CVD in patients with T2DM [38].

In the Diabetes Control and Complications Trial (DCCT), patients who received the conventional therapy for 6.5 years were compared to the group of patients who received the intensive insulin therapy. The intensive insulin therapy group showed a reduction in serious cardiovascular events, including cardiovascular death [39]. In the report from DCCT/EDIC, reporting the follow-up 
of 1429 patients over a period of 27 years, there was a large reduction in all-cause mortality in patients initially assigned to intensive therapy (43 deaths in the intensive therapy group versus 64 in the conventional group) [40]. The most common causes of death were CVD (22.4\%), cancer (19.6\%), and acute diabetes complications: hypoglycemia and diabetic ketoacidosis (17.8\%), and accidents or suicide (19.6\%). All-cause mortality was higher in patients with higher mean A1C levels and in those patients with additional renal disease. Surprisingly, the intensive insulin therapy for 6.5 years during the DCCT period reduced the risk of mortality in this group over the next 20 years compared with conventional therapy, despite an absence of a difference in $\mathrm{A} 1 \mathrm{C}$ values during the post-DCCT trial period.

Traditionally, diabetes and CVD were limited to Western countries, but it is suggested by recent evidence that these conditions are rapidly emerging in resourcelimited regions of the world, and estimates indicate that $80 \%$ of people with diabetes worldwide will die from CVD [41, 42].

\section{Myocardial infarction (MI)}

The risk for a first myocardial infarction (MI) in patients with diabetes is five times greater than in a population with similar risk factors but without diabetes. The risk for a recurrent MI is twice as high than people who previously had an MI but who do not have diabetes. These data indicate that the risk for a MI in patients with diabetes but who have not had a MI is similar to that in patients without diabetes but with a previous MI [42]. After sustaining a MI, patients with diabetes have a poorer long-term prognosis, increasing the risk for congestive heart failure and death [43]. Even the population with only insulin resistance (often a prodrome of developing T2DM) have an increased risk for CVD [44].

\section{Cerebrovascular disease}

The presence of diabetes adversely affects cerebrovascular circulation by increasing the risk of intracranial and extracranial atherosclerosis [45]. There is no difference in the prevalence and incidence of hemorrhagic stroke among patients with T2DMcompared to non-diabetic patients. Therefore, the excess risk of stroke is due to the high incidence of ischemic strokes in diabetic patients. People with diabetes have an increased occurrence of traditional risk factors for stroke, including high low-density lipoprotein (LDL) cholesterol, elevated blood pressure, smoking, low high-density lipoprotein (HDL) cholesterol, high levels of total triglycerides, central obesity, heart failure, and atrial fibrillation [46]. However, after these factors are controlled for, diabetes remains a strong predictor for stroke, suggesting that the presence of diabetes carries an additional and independent risk for stroke [47]. Besides being an independent risk factor for stroke, diabetes is also a risk factor for sudden and eventual death from stroke [47, 48]. After suffering from a stroke, patients with diabetes show more severe neurological deficits and disability, a poorer long-term prognosis, and a higher incidence of stroke recurrence than people without diabetes [49-53].

Although its precise relationship remains unclear, hyperglycemia and hyperinsulinemia appear to be a significant factor in stroke development [54-56]. Secondly, elevated blood levels of chronic inflammatory markers are associated with an increased risk for stroke [57]. Finally, the concomitant presence of diabetic retinopathy, microalbuminuria, proteinuria, and hyperuricemia are additional factors related to increased stroke risk [58-60].

\section{Peripheral artery disease}

Peripheral artery disease (PAD) is characterized by stenosis and/or occlusion of the lower-extremity arteries [61].

PAD, like the aforementioned vascular diseases, is related to the duration and severity of diabetes [62, 63]. As in other diabetes-related complications, hyperglycemia, specifically glycosylated hemoglobin ( $\mathrm{HbA1c}$ ), appears to be a significant factor in the development of PAD [64]. With every $1 \%$ increase in $\mathrm{HbA} 1 \mathrm{c}$, there was a $28 \%$ increase in the risk of PAD in the United Kingdom Prospective Diabetes Study (UKPDS) [65].

In the majority of patients, a large single-level disease often manifests initially as claudication. The multilevel disease can also manifest as claudication, provided that sufficient collateral circulation develops. Patients with diabetes are often presented with more advanced diseases and have a worse prognosis. Patients with diabetes are 15 times more likely to have a lower-extremity amputation than patients without diabetes [66].

Besides presenting with more advanced disease, there may also be an anatomic difference in the vascular distribution of PAD that contributes to a worse prognosis. The presence of diabetes is associated with more severe below-the-knee atherosclerosis [62]. Due to the anatomy and the small diameter of the arteries, a location has worse patency after open or endovascular surgery. In patients with diabetes, the anamnesis of physical activity will often identify patients with PAD symptoms and risk factors. However, symptoms of leg pain, the development of ulcers, and functional impairments can be due to PAD, and it can also be a manifestation of diabetic neuropathy (and often both) [62, 63].

For patients with an appropriate history and physical examination, the diagnosis of PAD is established with the measurement of the ankle-brachial index (ABI) [67]. For patients with appropriate symptoms and a normal $\mathrm{ABI}$, an $\mathrm{ABI}$ following exercise testing may provide additional information. For the measurement of the ABI, 
first, the systolic brachial blood pressure measurement at both arms, after which the systolic pressures of the dorsalis pedis and posterior tibial arteries are measured at malleolar level with an $8 \mathrm{MHz}$ Doppler sound in both legs. The ABI is calculated for each leg by dividing the highest systolic ankle pressure by the highest brachial systolic pressure. PAD was defined as a single ABI measurement of less than 0.9 in one or both legs [68].

$\mathrm{ABI}$ measurements are both a diagnostic and a prognostic tool [69]. In particular the ABI is very valuable for assessing the progression of PAD and has been reported as an independent marker for cardiac and vascular morbidity and mortality in patients with PAD [69]. The sensivity is lower in patients with diabetes, in particular in presence of peripheral neuropathy. In these cases, other tests have a much higher sensitivity (like toe blood pressure measurements of Doppler waveform analysis). These tests may be able to detect PAD, despite falsely elevated ABI. Besides that, a high $\mathrm{ABI}$ is a marker for medial artery calcification and is associated with neuropathy or chronic kidney disease. The earlier mentioned high ABI measurements seem to be linked with a particular form of PAD that is associated with a more diffused atherosclerosis and even microvascular damage. Patients with such a profile need special attention due to the high risk of limb amputation. ABI measurements can be used in patients with diabetes, but need to be interpreted with caution [69]. .Even in the pre-diabetic phase, in the population of patients with dysglycemia, $20 \%$ have an abnormal ABI compared with only $7 \%$ of patients with normal glucose levels [70].

\section{Treatment: lifestyle adjustments and risk factor management}

There is a consensus that a healthy lifestyle is recommended for the management of diabetes, including the prevention of T2DM [71]. Adapting positive self-care behaviors, such as blood glucose monitoring, a nutrientrich diet, and exercise are critical to disease progression [72]. Within healthy living, there are three main modifiable risk factors for diabetes: smoking, alcohol, and diet, each of these is discussed in turn.

\section{Smoking:}

- Smoking is determined as a risk factor for cardiovascular diseases and many more. Despite the extensive body of literature the exact mechanism and pathophysiological link between smoking, diabetes and glucose homeostasis is still not fully understood [73, 74]. Evidence shows that smoking increases the risk of diabetes and mortality $[75,76]$ and has a negative effect on the common conditions associated with diabetes. Studies have shown that smoking increases insulin resistance and negatively affects glucose control [77].

Smoking has an impact on microvascular complications such as nephropathy, retinopathy, and neuropathy. Evidence shows that smoking can increase the risk of both incidence and progression of neuropathy, especially with T1DM [74], and a meta-analysis of 19 observational studies showed an increased risk of neuropathy in smokers with T1DM and T2DM.

However, a meta-analysis of 73 studies found that the risk of diabetic retinopathy increased in T1D but significantly decreased in T2DM [78].

Neuropathy is one of the most common conditions associated with diabetic foot ulcers, with $78 \%$ of people presenting with neuropathy [26]. Smoking may exacerbate diabetic neuropathy partly through the mechanism of oxidative stress, leading to cellular damage and apoptosis (XIA). Other than glycemic control, there is no cure for neuropathy, and with the risks of poor wound healing and evidence of increased foot amputations as a result of Diabetes [79], smoking can have a negative impact on quality of life for people with diabetes.

Macrovascular complications include an increase in coronary heart disease compared with non-smoking counterparts, up to 4 times greater risk in Type 1 and T2DM [80]. A systematic review and meta-analysis with diabetic smokers and risk of cardiovascular events included 48 studies on smoking and risk of total mortality, 13 on cardiovascular mortality, 16 on total cardiovascular disease, 21 on coronary heart disease, 15 on stroke, 3 on peripheral artery disease and 4 on heart failure. Results showed an adjusted risk ratio (RR) associated with smoking of 1.55 for total mortality and 1.49 for cardiovascular mortality. For patients with diabetes, smoking increased the pooled RR for total cardiovascular disease as 1.44, coronary heart disease (CHD) as 1.51, stroke as 1.54, and heart failure as 1.43. The risk of PAD was more than double in patients with diabetes who smoke at $R R=2.15$ [81]. Evidence shows that smoking cessation demonstrates clear benefits in reducing or slowing the risk for cardiovascular morbidity and mortality in people with diabetes as it does for the general population [82].

\section{Alcohol:}

Alcohol (ethanol) is a risk factor for hypoglycemia in T1DM, and a systematic review of 13 studies showed consistent recommendations for alcohol to only be consumed alongside food intake [83]. With T2DM, studies show that moderate alcohol consumption may be protective, reducing the risk of cardiovascular disease and mortality [84], decreasing the incidence of diabetes in many studies, but heavy and/ 
or binge drinkers are at increased risk for diabetes; the type of alcohol, sex, and body mass index (BMI) can additionally affect outcomes [85].

However, alcohol use may detrimentally impact positive health behaviors. Alcohol consumption may lead to decreased compliance with diet, medication, exercise, and glucose self-monitoring, regardless of the amount of alcohol consumed [72]. Given extant evidence that moderate alcohol intake may have cardiovascular benefits for patients with diabetes, a balanced examination of tradeoffs between cardiovascular benefits against the potential risk of lower adherence with self-care behaviors warrants further investigation [86].

\section{Diet:}

Diet has always been central to understanding diabetes, with historical accounts of symptoms attributed to the disease related to food consumption such as sweets and carbohydrates [2]. The goal of diet in diabetes (type 1 and 2) is to decrease the risk of diabetes and CVD by promoting healthy food choices. The American Diabetes Association (ADA) recommends the role of diet to achieve and maintain blood glucose levels in as normal a range as possible, lipid and lipoprotein profile that reduces the risk of vascular disease and regulated blood pressure while preventing/slowing the rate of complications of diabetes [87].

Adhering to the recommended amounts of macro and micronutrients of carbohydrates, fat, protein, vitamins, and minerals form part of the underlying mechanisms needed to regulate glucose metabolism to manage diabetes effectively [88], whether alone or in combination with drug therapy. Studies have shown a positive association between diets high in sugar and the development of T2DM [89], and an increase in the risk of insulin resistance and T2DM was found in people with high intakes of red meat, sweets, and fried food [90]. A systematic review of low carbohydrate, fasting, macrobiotic, Mediterranean, vegetarian, and vegan diets showed that the latter three offered better glycaemic control in individuals with T2DM [91].

\section{Treatment: medication and bariatric and metabolic surgery (BMS)}

In case lifestyle adjustments are not giving satisfactory results, the second line of treatment is usually medication, particularly metformin and/or sulfonylureas (in the case of T2DM). In the case of T1DM, the preferred treatment is insulin replacement $[6,7,10]$. With the changing landscape of pharmacotherapy (for example, GLP-1 agonists) and the increasing understanding of the physiology of diabetes remission after BMS, the physiology became even more complex, and we might need a diabetes re-classification. To understand this, we will discuss the trials assessing clinical outcomes of BMS in patients with T2DM $[6,7,10]$.

The prevalence of diabetes is increasing worldwide, and most of the cases are T2DM. The relationship between T2DM and obesity is well established, and surgical treatment is widely used for patients with obesity with T2DM. T2DM is associated with obesity and multiple metabolic derangements, leading to increased morbidity, mortality, and financial burden. Randomized controlled trials (RCT) demonstrate that BS is considered the most effective treatment for obesity treatment by weight loss and comorbidity resolution and has recently shown the efficacy and superiority of surgery over to the best medical therapy alone, achieving improvement hyperglycemia $[92,93]$. Table 2 shows the most recent level 1 evidence indicating the long-term efficacy of $\mathrm{BS}$ in the remission of T2DM compared to medical therapy.

The mechanisms seem to extend beyond the magnitude of weight loss alone and include improvements in incretin profiles, insulin secretion, and insulin sensitivity. MS offers similar benefits in individuals with BMI 30$35 \mathrm{~kg} / \mathrm{m} 2$, compared with those with higher BMI. There is a better understanding of gut hormones and nonhormonal factors on weight loss and glucose metabolism.

A five-year follow-up analysis of STAMPEDE (Surgical Treatment and Medications Potentially Eradicate Diabetes Efficiently) trial was among the first to provide level I evidence on the efficacy of BS in T2DM remission and control [93]. Long-term data from the Swedish Obese Subjects (SOS) study [97] suggest that T2DM remission decreases over time. However, this observation is based mostly on results with a procedure that is no longer performed.

A wide variety of BMS procedures initially designed to promote weight loss have been found to powerfully treat T2DM, causing remission in most cases, through diverse mechanisms additional to the secondary consequences of weight loss. The Fifth IFSO Global Registry Report reported that almost 833,687 metabolic procedures were performed worldwide in 2019 [98], of them Sleeve gastrectomy (SG) remained the most commonly performed bariatric procedure $(N=305,242 ; 58.6 \%)$ followed by Roux-en-Y gastric bypass (RYGB) $(N=162,613 ; 31.2 \%)$, One anastomosis gastric bypass (OAGB) $(N=21,613$; $4.1 \%)$, Gastric band (AGB) $(N=19,255 ; 3.7 \%)$, and Duodenal switch with sleeve $(N=2554 ; 0.5 \%)$.

BS is currently (according to national and international guidelines) only advised in patients with T2DM with a BMI $\geq 35 \mathrm{~kg} / \mathrm{m}^{2}$. This somewhat outdated evidence is being challenged by several studies that indicate that patient a lower BMI and T2DM can also benefit from MS. A recent meta-analysis showed that diabetes remission is 
Table 2 Recent level 1 evidence confirming the superiority of bariatric surgery (BS) over medical therapy as a treatment of type 2 diabetes mellitus (T2DM)

Khorgami et al. 2019 [94] Meta-analysis of 7 RCTs found that the chance of remission of T2DM was significantly higher after BS compared with medical management after at least 2-year follow-up (risk ratio (RR) $=10,95 \% \mathrm{Cl}$ 5.5-17.9, $p<0.001$ ).

Sharples \& Mahawar 2020 [95]

A meta-analysis examining 5-year outcomes reported that the resolution of T2DM was 37.4 and $27.5 \%$ after RYGB and SG respectively.

Mingrone et al. 2021 [96]

RCT showed the 10-year remission rates for T2DM were significantly higher in the surgical group (BPD 50\%, RYGB 25\%, medical therapy 5.5\%)

Abbreviations: RCT Randomised controlled trial, T2DM type 2 diabetes mellitus, BS bariatric surgery, RYGB Roux en Y Gastric Bypass, SG Sleeve Gastrectomy, BPD Biliopancreatic diversion

comparable between patients with a BMI $\geq 35 \mathrm{~kg} / \mathrm{m}^{2}$ and patients with a $\mathrm{BMI}<35 \mathrm{~kg} / \mathrm{m}^{2}(71 \%$ vs. $72 \%$, respectively) [99].

However, AGB, SG, SADI-S (Single-Anastomosis Duodenal Switch), RYGB, and OAGB incorporate different surgical approaches and differential effects on metabolic outcomes.

RYGB and SG are the most commonly performed bariatric surgical procedures [100-102] and result in significant and sustained weight loss accompanied by dramatic glucose metabolism changes [103, 104]. However, surgeons continue to explore other procedures that may carry advantages in surgical or metabolic improvements. Among these procedures are the OAGB and the SADI$\mathrm{S}$, both of which produce significant improvements in body weight and glucose homeostasis [105-107].

Commonly speaking, surgical procedures with intestinal diversion and/or duodenal-jejunal exclusion have consistently shown beneficial effects on glucose homeostasis by reducing insulin resistance and increasing insulin secretion [108]. A recent meta-analysis reported an overall remission rate of $78.1 \%$ for diabetic patients undergoing BS $[102,109]$.

A RCT found that OAGB produced weight loss comparative to SG [110], although OAGB was associated with better glycaemic control. A recent report on the weight outcomes of SADI-S vs. RYGB indicated no differences in weight loss or diabetes remission [111-113]. There is now enough evidence to state that BS reduces mortality in patients with diabetes. In the analysis by Adams et al. [114], deaths attributed to diabetes were reduced by $92 \%$.

\section{Laparoscopic adjustable gastric banding (LAGB)}

A dramatic metabolic improvement associated with frequent complete remission of recent-onset T2DM has recently been reported 2 years after LAGB $[98,115,116]$. A meta-analysis [109] reported an overall remission of diabetes undergoing BS. However, not all bariatric procedures were equally effective. Instead, a steady trend of increasing efficacy correlated with the degree of weight loss, from gastric banding at the lower end of the spectrum to biliopancreatic diversion and duodenal switch yielding the greatest results. In a single- institution study [117] of the 5-year outcomes after LAGB, we found a $40 \%$ rate of remission and a $72 \% \mathrm{im}$ provement rate. Although such results were not as positive as those from the studies of RYGB, they nonetheless represent a substantial benefit compared with nonoperative traditional diabetes management. Despite the significant improvement in individual metabolic parameters, $73 \%$ of patients remained diabetic at 5 years in this intention-to-treat analysis. Moreover, nine $(41 \%)$ of the 22 diabetic patients failed to meet the 7\% HbA1c target level promoted by the ADA [118].

\section{Roux-en-Y gastric bypass (RYGB)}

Two large case-series studies, by Pories et al. [119] and Schauer et al. [120], focused principally on diabetes outcomes after RYGB. In the former study, mean fasting blood glucose (FBG) decreased from clearly diabetic values to near-normal levels (117 mg\%), and HbA1c fell to normal levels $(6.6 \%)$ without diabetes medicines in $89 \%$ of patients. In the latest study by Schauer et al. [92], researchers provided an in-depth evaluation of the clinical outcome in 240 patients with morbid obesity and diabetes with a follow-up rate of $80 \%$.

It was shown that there was a BMI decrease from 50.1 $\mathrm{kg} / \mathrm{m}^{2}$ to $34 \mathrm{~kg} / \mathrm{m}^{2}$ with a mean concomitant excess weight loss of $60 \%$. This resulted in complete remission of the T2DM in $83 \%$ of the patients (normale fasting plasma glucose and HbA1c concentrations) or a significant improvement in $17 \%$ of the patients. Both also resulted in a significant decrease in usage of oral antidiabetic agents (80\%) and insulin (79\%). followed surgical treatment. Patients with the shortest duration ( $<5$ years), the mildest form of type 2 diabetes (diet controlled), and the greatest weight loss after surgery were most likely to achieve complete resolution of T2DM $[92,93]$.

The multi-center SOS study compared BS (LAGB, $n=$ 156; VBG, $n=451$; RYGB, $n=34$ ) with medical weightloss treatment in well-matched obese patients [121]. BS caused an average $16.1 \%$ weight loss at 10 years, compared with a small weight gain in control subjects. Mean weight loss was greater after RYGB $(-25.0 \mathrm{~kg})$ than after LAGB $(-13.2 \mathrm{~kg})$ or VBG $(-16.5 \mathrm{~kg})$. Mean FBG tended to increase during the study in non-surgical controls $(+$ $18.7 \%$ at 10 years), whereas a substantial decrease was 
seen in surgical patients at 2 years $(-13.6 \%)$ and 10 years $(-2.5 \%)$. The risk of diabetes was more than three times lower for surgically treated patients at 10 years, and recovery rates from diabetes were three times greater [121].

\section{Sleeve gastrectomy (SG)}

As SG gained popularity, this procedure's effectiveness on weight loss and diabetes remission began to be scrutinized [122]. Studies have compared the effectiveness of SG to RYGB in terms of diabetes remission and found comparable results. A study comparing metabolic syndrome of severely obese T2DM subjects following SG and RYGB surgery found equivalent resolution rates, with $84.6 \%$ of both cohorts achieving resolution of T2DM at 1 year $(p=0.618)$ [123]. Another study comparing RYGB and SG in patients with obesity found a remission rate of 22 and $21.5 \%$, respectively, 1 and 2 years post-surgery [124].

\section{One anastomosis gastric bypass - mini gastric bypass (OAGB-MGB)}

In terms of metabolic efficacy related to T2DM, OAGB MGB seems to give similar (or even better results) than SG and RYGB. In a systematic review done by Parmar and colleagues it was seen that the T2DM and hypertension remission rates were 83.7 and $66.9 \%$ respectively [125].

Quan Y et al. [126] performed a systematic review comparing the efficacy of laparoscopic OAGB-MGB for obesity and T2DM with other bariatric procedures. This review included 6 studies comparing OAGB-MGB with LSG. They reported a significantly higher T2DM remission rate in OAGB-MGB compared with LSG. Also, OAGB-MGB had a significantly lower revision rate. In Quan et al.'s systematic review of 5 studies comparing outcomes of OAGB-MGB and RYGB, they reported that OAGB-MGB had significantly better \%EWL and remission of T2DM and had fewer complications [126].

Lee et al. [111] reported more than $80 \%$ resolution of metabolic syndrome in their retrospective series of 1163 patients compared to RYGB. More recently, the YOMEGA RCT [127] showed that $60 \%$ of diabetic patients achieved complete remission with OAGB-MGB compared with $38 \%$ with RYGB. Partial remission rates were 10 and $6 \%$, respectively.

Recently, Sjöström et al. reported that in patients with obesity and T2DM from the SOS trial, a 2-cohort prospective observational study with long-term follow-up, BMS was more frequently associated with T2DM remission and fewer micro and macrovascular complications than usual non-surgical care [97]. These findings were identified despite most patients having undergone purely restrictive procedures such as the vertical banded gastroplasty, which have not been shown to have weight-independent metabolic changes.

\section{Do we need a diabetes re-classification?}

Bariatric surgery is increasingly being proposed as a treatment option for obesity and T2DM because of failure of medical management. Many surgical techniques exist which modulate different aspects of gastrointestinal physiology and will result in weight loss and remission of comorbidities [102, 128]. However, with so many physiological modulators in place, such as the gastrointestinal hormones like GLP-1 and ghrelin, PYY, oxyntomodulin, creating a new classification for the spectrum of diabetes and related disease is a major yet very difficult task.

In terms of mechanistic aspects of BMS, there is a major distinction between bariatric procedures that rely on restriction, malabsorption, or a combination of both $[101,102]$. Weight loss and glycaemic effects were traditionally thought to be results of caloric restriction and/ or malabsorption of ingested nutrients. The systematic review done by Panunzi et al. [99] showed that diabetes remission rates were similar in patients with a $\mathrm{BMI}>35$ $\mathrm{kg} / \mathrm{m}^{2}$ compared with patients with a $\mathrm{BMI}<35 \mathrm{~kg} \mathrm{~m}^{2}$. Also the baseline BMI did not have any effect on diabetes remission rates [99]. Still, more recent studies have demonstrated that changes in the physiology of energy balance and body fat mass are the primary mechanisms. Indeed, widespread alterations in the secretion and activity of hormones and neurotransmitters affecting appetite, satiety, energy expenditure, and glucose metabolism in response to these surgical procedures have been increasingly recognized [109, 129].

In a meta-analysis and systematic review of existing RCTs directly comparing various surgical vs. non-surgical treatment for diabetes, BS was associated with greater weight loss, higher remission rates of T2DM and metabolic syndrome, better lipid profiles, greater improvement in the quality of life, and substantial reductions in medication requirements [130, 131]. Mechanistic evidence further suggests that the duodenum and jejunum (proximal gut) bypass or exclusion may directly benefit glycemic control beyond those mediated by weight loss [132].

Buchwald et al. [102] reported that complete resolution of T2DM (defined as discontinuation of all diabetes-related medications and blood glucose levels within the normal range) occurred in $78.1 \%$ of cases after BS. This percentage increased to $86.6 \%$ when counting patients reporting improved glycemic control, and diabetes resolution occurred in concomitance with an average weight loss of $38.5 \mathrm{~kg}$ ( $55.9 \%$ of the excess weight) [102]. However, Panunzi et al. [99] reported that diabetes remission after BMS (in 94,579 surgical patients) was independent of the mean baseline BMI ( $\geq 35$ 
$\mathrm{kg} / \mathrm{m}^{2}$ compared with $<35 \mathrm{~kg} / \mathrm{m}^{2}$. The diabetes remission rates were similar ( $71 \%$ vs. $72 \%$, respectively) [99].

When looking at an updated diabetes classification, we need to take into account the different modes of action of the gastrointestinal hormones [133]. As scientists, we are tempted to correlate the effects of BS with the change of the gastrointestinal hormones postoperatively [134]. In the remission of T2DM after BS, there is now intriguing evidence that GLP-1 receptor agonists are not able to promote remission of T2DM as surgical procedures do. They are effective agents in the treatment of T2DM, and some even consider them as BS 'mimetics' because of the improved glycaemic control and weight loss during therapy [134-137]. Unfortunately, this is not the case [138].

\section{Conclusion}

Diabetes Mellitus is a complex multifactorial disease, leading to high morbidity and mortality. With the development of newer drugs and improved surgical options, our knowledge of diabetes and its physiology increased incrementally. However, with this increase in knowledge, we are still not able to fully understand its pathophysiology and therefore based on the current literature a new reclassification is difficult to made. Future research will hopefully guide clinicians to optimal medical and/or surgical treatment for diabetes and provide further structure in a potential reclassification of diabetes.

\section{Acknowledgements}

None.

\section{Authors' contributions}

Collecting data and articles for the review: NS, YG, TP, WY, RK, EW, RS, ZE, DR, $\mathrm{KM}, \mathrm{CP}, \mathrm{BM}$, and SP. Writing the manuscript: NS, YG, TP, WY, RK, EW, RS, ZE, $D R, K M, C P, B M$, and SP. Final approval: NS, YG, TP, WY, RK, EW, RS, ZE, DR, $\mathrm{KM}, \mathrm{CP}, \mathrm{BM}$, and $\mathrm{SP}$.

\section{Funding}

None.

\section{Availability of data and materials}

Upon request, please contact the corresponding author (dr. S. Pouwels).

\section{Declarations}

Ethics approval and consent to participate Not applicable.

\section{Consent for publication}

Not applicable.

\section{Competing interests}

None.

\section{Author details}

${ }^{1}$ Department of Surgery, Holy Family Hospital, Nazareth, Israel. ${ }^{2}$ the Azrieli Faculty of Medicine, Bar-llan University, Safed, Israel. ${ }^{3}$ Faculty of Health Sciences and Wellbeing, University of Sunderland, Sunderland, UK. ${ }^{4}$ Facultad de Psycologia, Universidad Anahuac Mexico, Mexico City, Mexico. ${ }^{5}$ Department of Abdominal Surgery, University Medical Center Ljubljana, Zaloška cesta, Ljubljana, Slovenia. ${ }^{6}$ Department of Metabolic and Bariatric
Surgery, The First Affiliated Hospital of Jinan University, 613 Huangpu Avenue West, Guangzhou, Guangdong Province, China. 'CHU Félix Guyon, Allée des Topazes, Saint-Denis, France. ${ }^{8}$ Department of Vascular Surgery, Medisch Spectrum Twente, Enschede, The Netherlands. 'Bariatric and Upper GI Unit, Birmingham Heartlands Hospital, University Hospital Birmingham NHS Foundation Trust, Birmingham, UK. ${ }^{10}$ Department of Dermatology, Amphia Hospital, Breda, The Netherlands. " Department of Intensive Care Medicine, Elisabeth-Tweesteden Hospital, Tilburg, The Netherlands. ${ }^{12}$ Bariatric Unit, South Tyneside and Sunderland NHS Foundation Trust, Sunderland, UK.

${ }^{13}$ Department of Surgery, Whittington Health NHS Trust, London, UK. ${ }^{14}$ East Midlands Bariatric and Metabolic Institute, University Hospital of Derby and Burton NHS Foundation Trust, Burton, UK. ${ }^{15}$ Department of Intensive Care Medicine, ETZ Elisabeth, Hilvarenbeekseweg 60, P.O. Box 90151, 5000 LC Tilburg, The Netherlands.

Received: 12 July 2021 Accepted: 22 December 2021

Published online: 07 January 2022

\section{References}

1. Diabetes UK. Diabetes history. 2019. Available from: https://www.diabetes. co.uk/diabetes-history.html.

2. Karamanou M, Protogerou A, Tsoucalas G, Androutsos G, PoulakouRebelakou E. Milestones in the history of diabetes mellitus: the main contributors. World J Diabetes. 2016;7(1):1-7.

3. UK D. Diabetes history. 2019. [cited 2021]. Available from: https:/www.dia betes.co.uk/diabetes-history.html.

4. Today MN. Diabetes: past treatments, new discoveries. 2021. Available from: https://www.medicalnewstoday.com/articles/317484.

5. Sami W, Ansari T, Butt NS, Hamid MRA. Effect of diet on type 2 diabetes mellitus: a review. Int J Health Sci (Qassim). 2017;11(2):65-71.

6. American Diabetes Association 2. Classification and diagnosis of diabetes: standards of medical care in diabetes-2018. Diabetes Care. 2018;41(Suppl 1): S13-27.

7. American Diabetes Association 6. Glycemic targets: standards of medical care in diabetes-2019. Diabetes Care. 2019:42(Suppl 1):S61-70.

8. White JR Jr. A brief history of the development of diabetes medications. Diab Spectr. 2014:27(2):82-6.

9. Association AD. 2. Classification and diagnosis of diabetes. Diabetes Care. 2015;38(Supplement 1):S8

10. American Diabetes A. Diagnosis and classification of diabetes mellitus. Diabetes Care. 2010;33(Suppl 1):S62-S9.

11. DiMeglio LA, Evans-Molina C, Oram RA. Type 1 diabetes. Lancet. 2018; 391(10138):2449-62.

12. Rogers MAM, Kim C, Banerjee T, Lee JM. Fluctuations in the incidence of type 1 diabetes in the United States from 2001 to 2015: a longitudinal study. BMC Med. 2017:15(1):199.

13. Skyler JS, Bakris GL, Bonifacio E, Darsow T, Eckel RH, Groop L, et al. Differentiation of diabetes by pathophysiology, natural history, and prognosis. Diabetes. 2017;66(2):241-55.

14. TEDDY Study Group. The environmental determinants of diabetes in the young (TEDDY) study. Ann N Y Acad Sci 2008;1150:1-13.

15. Galicia-Garcia U, Benito-Vicente A, Jebari S, Larrea-Sebal A, Siddiqi H, Uribe KB, et al. Pathophysiology of type 2 diabetes mellitus. Int J Mol Sci. 2020; 21(17):6275

16. Chatterjee S, Khunti K, Davies MJ. Type 2 diabetes. Lancet. 2017;389(10085): 2239-51.

17. UK Prospective Diabetes Study (UKPDS). VIII. Study design, progress and performance. Diabetologia. 1991;34(12):877-90.

18. Rahman S, Rahman T, Ismail AA, Rashid AR. Diabetes-associated macrovasculopathy: pathophysiology and pathogenesis. Diabetes Obes Metab. 2007;9(6):767-80.

19. Molitch ME, Steffes MW, Cleary PA, Nathan DM. Baseline analysis of renal function in the Diabetes control and complications trial. The diabetes control and complications trial research group [corrected]. Kidney Int. 1993; 43(3):668-74.

20. Dahl-Jørgensen K, Bjøro T, Kierulf P, Sandvik L, Bangstad HJ, Hanssen KF. Long-term glycemic control and kidney function in insulin-dependent diabetes mellitus. Kidney Int. 1992:41(4):920-3.

21. Barzilay J, Warram JH, Bak M, Laffel LM, Canessa M, Krolewski AS. Predisposition to hypertension: risk factor for nephropathy and hypertension in IDDM. Kidney Int. 1992;41(4):723-30. 
22. Nathan DM, Genuth S, Lachin J, Cleary P, Crofford O, Davis M, et al. The effect of intensive treatment of diabetes on the development and progression of long-term complications in insulin-dependent diabetes mellitus. N Engl J Med. 1993;329(14):977-86.

23. The relationship of glycemic exposure ( $\mathrm{HbA1c}$ ) to the risk of development and progression of retinopathy in the diabetes control and complications trial. Diabetes. 1995;44(8):968-83.

24. Holman RR, Paul SK, Bethel MA, Matthews DR, Neil HA. 10-year follow-up of intensive glucose control in type 2 diabetes. N Engl J Med. 2008;359(15): 1577-89.

25. Ismail-Beigi F, Craven T, Banerii MA, Basile J, Calles J, Cohen RM, et al. Effect of intensive treatment of hyperglycaemia on microvascular outcomes in type 2 diabetes: an analysis of the ACCORD randomised trial. Lancet. 2010; 376(9739):419-30.

26. Dinh $T L$, Veves A. A review of the mechanisms implicated in the pathogenesis of the diabetic foot. Int J Low Extrem Wounds. 2005;4(3):154-9.

27. Skyler JS, Bergenstal R, Bonow RO, Buse J, Deedwania P, Gale EA, et al. Intensive glycemic control and the prevention of cardiovascular events: implications of the ACCORD, ADVANCE, and VA diabetes trials: a position statement of the American Diabetes Association and a scientific statement of the American College of Cardiology Foundation and the American Heart Association. Circulation. 2009;119(2):351-7.

28. Holman RR, Paul SK, Bethel MA, Neil HA, Matthews DR. Long-term follow-up after tight control of blood pressure in type 2 diabetes. N Engl J Med. 2008; 359(15):1565-76.

29. Ohkubo Y, Kishikawa H, Araki E, Miyata T, Isami S, Motoyoshi S, et al. Intensive insulin therapy prevents the progression of diabetic microvascular complications in Japanese patients with non-insulin-dependent diabetes mellitus: a randomized prospective 6-year study. Diabetes Res Clin Pract. 1995;28(2):103-17.

30. Zoungas S, Chalmers J, Neal B, Billot L, Li Q, Hirakawa Y, et al. Follow-up of blood-pressure lowering and glucose control in type 2 diabetes. N Engl J Med. 2014;371(15):1392-406.

31. Chew EY, Ambrosius WT, Davis MD, Danis RP, Gangaputra S, Greven CM, et al. Effects of medical therapies on retinopathy progression in type 2 diabetes. N Engl J Med. 2010;363(3):233-44.

32. Wei $\mathrm{N}$, Zheng $\mathrm{H}$, Nathan DM. Empirically establishing blood glucose targets to achieve HbA1c goals. Diabetes Care. 2014;37(4):1048-51.

33. Laakso M. Hyperglycemia and cardiovascular disease in type 2 diabetes. Diabetes. 1999:48(5):937-42.

34. Buyken AE, von Eckardstein A, Schulte H, Cullen P, Assmann G. Type 2 diabetes mellitus and risk of coronary heart disease: results of the 10-year follow-up of the PROCAM study. Eur J Cardiovasc Prev Rehabil. 2007;14(2): 230-6.

35. Bonora E, Formentini G, Calcaterra F, Lombardi S, Marini F, Zenari L, et al. HOMA-estimated insulin resistance is an independent predictor of cardiovascular disease in type 2 diabetic subjects: prospective data from the verona diabetes complications study. Diabetes Care. 2002;25(7):1135-41.

36. Reusch JE, Draznin BB. Atherosclerosis in diabetes and insulin resistance. Diabetes Obes Metab. 2007;9(4):455-63.

37. Expert Panel on Detection, Evaluation, and Treatment of High Blood Cholesterol in Adults. Executive summary of the third report of the National Cholesterol Education Program (NCEP) expert panel on detection, evaluation, and treatment of high blood cholesterol in adults (adult treatment panel III). Jama. 2001;285(19):2486-97.

38. Beckman JA, Creager MA, Libby P. Diabetes and atherosclerosis: epidemiology, pathophysiology, and management. Jama. 2002;287(19): 2570-81.

39. Nathan DM, Bayless M, Cleary P, Genuth S, Gubitosi-Klug R, Lachin JM, et al. Diabetes control and complications trial/epidemiology of diabetes interventions and complications study at 30 years: advances and contributions. Diabetes. 2013;62(12):3976-86.

40. Orchard TJ, Nathan DM, Zinman B, Cleary P, Brillon D, Backlund JY, et al. Association between 7 years of intensive treatment of type 1 diabetes and long-term mortality. Jama. 2015;313(1):45-53.

41. Turner R, Cull C, Holman R. United Kingdom prospective diabetes study 17: a 9-year update of a randomized, controlled trial on the effect of improved metabolic control on complications in non-insulin-dependent diabetes mellitus. Ann Intern Med. 1996;124(1 Pt 2):136-45.

42. Haffner SM, Lehto S, Rönnemaa T, Pyörälä K, Laakso M. Mortality from coronary heart disease in subjects with type 2 diabetes and in non-diabetic subjects with and without prior myocardial infarction. N Engl J Med. 1998; 339(4):229-34.

43. Malmberg K, Yusuf S, Gerstein HC, Brown J, Zhao F, Hunt D, et al. Impact of diabetes on long-term prognosis in patients with unstable angina and nonQ-wave myocardial infarction: results of the OASIS (organization to assess strategies for ischemic syndromes) registry. Circulation. 2000;102(9):1014-9.

44. Facchini FS, Hua N, Abbasi F, Reaven GM. Insulin resistance as a predictor of age-related diseases. J Clin Endocrinol Metab. 2001;86(8):3574-8.

45. Fabris F, Zanocchi M, Bo M, Fonte G, Poli L, Bergoglio I, et al. Carotid plaque, aging, and risk factors. A study of 457 subjects. Stroke. 1994;25(6): $1133-40$.

46. Stegmayr B, Asplund K. Diabetes as a risk factor for stroke. A population perspective. Diabetologia. 1995;38(9):1061-8.

47. Tuomilehto J, Rastenyte D, Jousilahti P, Sarti C, Vartiainen E. Diabetes mellitus as a risk factor for death from stroke. Prospective study of the middle-aged Finnish population. Stroke. 1996;27(2):210-5.

48. Håheim LL, Holme I, Hjermann I, Leren P. Nonfasting serum glucose and the risk of fatal stroke in diabetic and non-diabetic subjects. 18-year followup of the Oslo study. Stroke. 1995;26(5):774-7.

49. Ribo M, Molina C, Montaner J, Rubiera M, Delgado-Mederos R, Arenillas JF, et al. Acute hyperglycemia state is associated with lower tPA-induced recanalization rates in stroke patients. Stroke. 2005;36(8):1705-9.

50. Parsons MW, Barber PA, Desmond PM, Baird TA, Darby DG, Byrnes G, et al. Acute hyperglycemia adversely affects stroke outcome: a magnetic resonance imaging and spectroscopy study. Ann Neurol. 2002;52(1):20-8.

51. Megherbi SE, Milan C, Minier D, Couvreur G, Osseby GV, Tilling K, et al. Association between diabetes and stroke subtype on survival and functional outcome 3 months after stroke: data from the European BIOMED stroke project. Stroke. 2003;34(3):688-94.

52. Sprafka JM, Virnig BA, Shahar E, McGovern PG. Trends in diabetes prevalence among stroke patients and the effect of diabetes on stroke survival: the Minnesota heart survey. Diabet Med. 1994;11(7):678-84.

53. Elneihoum AM, Göransson M, Falke P, Janzon L. Three-year survival and recurrence after stroke in Malmö, Sweden: an analysis of stroke registry data. Stroke. 1998;29(10):2114-7.

54. Shinozaki K, Naritomi H, Shimizu T, Suzuki M, Ikebuchi M, Sawada T, et al. Role of insulin resistance associated with compensatory hyperinsulinemia in ischemic stroke. Stroke. 1996;27(1):37-43.

55. Zunker P, Schick A, Buschmann HC, Georgiadis D, Nabavi DG, Edelmann M, et al. Hyperinsulinism and cerebral microangiopathy. Stroke. 1996; 27(2):219-23

56. Davis TM, Millns H, Stratton IM, Holman RR, Turner RC. Risk factors for stroke in type 2 diabetes mellitus: United Kingdom Prospective Diabetes Study (UKPDS) 29. Arch Intern Med. 1999;159(10):1097-103.

57. Engström G, Stavenow L, Hedblad B, Lind P, Eriksson KF, Janzon L, et al. Inflammation-sensitive plasma proteins, diabetes, and mortality and incidence of myocardial infarction and stroke: a population-based study. Diabetes. 2003;52(2):442-7.

58. Sasaki A, Horiuchi N, Hasegawa K, Uehara M. Mortality from coronary heart disease and cerebrovascular disease and associated risk factors in diabetic patients in Osaka District, Japan. Diabetes Res Clin Pract. 1995;27(1):77-83.

59. Guerrero-Romero F, Rodríguez-Morán M. Proteinuria is an independent risk factor for ischemic stroke in non-insulin-dependent diabetes mellitus. Stroke. 1999;30(9):1787-91.

60. Lehto S, Niskanen L, Rönnemaa T, Laakso M. Serum uric acid is a strong predictor of stroke in patients with non-insulin-dependent diabetes mellitus. Stroke. 1998;29(3):635-9.

61. American Diabetes Association. Peripheral arterial disease in people with diabetes. Diabetes Care. 2003:26(12):3333-41.

62. Jude EB, Oyibo SO, Chalmers N, Boulton AJ. Peripheral arterial disease in diabetic and non-diabetic patients: a comparison of severity and outcome. Diabetes Care. 2001;24(8):1433-7.

63. Al-Delaimy WK, Merchant AT, Rimm EB, Willett WC, Stampfer MJ, Hu FB. Effect of type 2 diabetes and its duration on the risk of peripheral arterial disease among men. Am J Med. 2004;116(4):236-40.

64. Selvin E, Marinopoulos S, Berkenblit G, Rami T, Brancati FL, Powe NR, et al. Meta-analysis: glycosylated hemoglobin and cardiovascular disease in diabetes mellitus. Ann Intern Med. 2004;141(6):421-31.

65. Adler Al, Stevens RJ, Neil A, Stratton IM, Boulton AJ, Holman RR. UKPDS 59: hyperglycemia and other potentially modifiable risk factors for peripheral vascular disease in type 2 diabetes. Diabetes Care. 2002;25(5):894-9. 
66. Adler Al, Boyko EJ, Ahroni JH, Smith DG. Lower-extremity amputation in diabetes. The independent effects of peripheral vascular disease, sensory neuropathy, and foot ulcers. Diabetes Care. 1999;22(7):1029-35.

67. Bendermacher BL, Teijink JA, Willigendael EM, Bartelink ML, Büller HR, Peters $\mathrm{RJ}$, et al. Symptomatic peripheral arterial disease: the value of a validated questionnaire and a clinical decision rule. Br J Gen Pract. 2006;56(533):932-7.

68. Bendermacher BL, Teijink JA, Willigendael EM, Bartelink ML, Peters RJ, Langenberg $\mathrm{M}$, et al. Applicability of the ankle-brachial-index measurement as screening device for high cardiovascular risk: an observational study. BMC Cardiovasc Disord. 2012;12:59.

69. Potier L, Abi Khalil C, Mohammedi K, Roussel R. Use and utility of ankle brachial index in patients with diabetes. Eur J Vasc Endovasc Surg. 2011; 41(1):110-6.

70. Beks PJ, Mackaay AJ, de Neeling JN, de Vries H, Bouter LM, Heine RJ. Peripheral arterial disease in relation to glycaemic level in an elderly Caucasian population: the Hoorn study. Diabetologia. 1995;38(1):86-96.

71. Zhang Y, Pan XF, Chen J, Xia L, Cao A, Zhang Y, et al. Combined lifestyle factors and risk of incident type 2 diabetes and prognosis among individuals with type 2 diabetes: a systematic review and meta-analysis of prospective cohort studies. Diabetologia. 2020;63(1):21-33.

72. Engler PA, Ramsey SE, Smith RJ. Alcohol use of diabetes patients: the need for assessment and intervention. Acta Diabetol. 2013;50(2):93-9.

73. Chang SA. Smoking and type 2 diabetes mellitus. Diabetes Metab J. 2012; 36(6):399-403

74. Campagna D, Alamo A, Di Pino A, Russo C, Calogero AE, Purrello F, et al. Smoking and diabetes: dangerous liaisons and confusing relationships. Diabetol Metab Syndr. 2019;11(1):85.

75. Jee SH, Foong AW, Hur NW, Samet JM. Smoking and risk for diabetes incidence and mortality in Korean men and women. Diabetes Care. 2010; 33(12):2567-72.

76. Willi C, Bodenmann P, Ghali WA, Faris PD, Cornuz J. Active smoking and the risk of type 2 diabetes: a systematic review and meta-analysis. Jama. 2007; 298(22):2654-64.

77. Haj Mouhamed D, Ezzaher A, Neffati F, Douki W, Gaha L, Najjar MF. Effect of cigarette smoking on insulin resistance risk. Ann Cardiol Angeiol. 2016;65(1):21-5.

78. Cai X, Chen Y, Yang W, Gao X, Han X, Ji L. The association of smoking and risk of diabetic retinopathy in patients with type 1 and type 2 diabetes: a meta-analysis. Endocrine. 2018;62(2):299-306.

79. Tesfaye S, Chaturvedi N, Eaton SE, Ward JD, Manes C, lonescu-Tirgoviste C, et al. Vascular risk factors and diabetic neuropathy. N Engl J Med. 2005; 352(4):341-50

80. Rawshani A, Rawshani A, Franzén S, Eliasson B, Svensson AM, Miftaraj M, et al. Mortality and cardiovascular disease in type 1 and type 2 diabetes. $N$ Engl J Med. 2017;376(15):1407-18.

81. Pan A, Wang Y, Talaei M, Hu FB. Relation of smoking with total mortality and cardiovascular events among patients with diabetes mellitus. Circulation. 2015;132(19):1795-804.

82. Pirie K, Peto R, Reeves GK, Green J, Beral V, Million Women Study C. The 21st century hazards of smoking and benefits of stopping: a prospective study of one million women in the UK. Lancet. 2013; 381(9861):133-41.

83. Tetzschner R, Nørgaard K, Ranjan A. Effects of alcohol on plasma glucose and prevention of alcohol-induced hypoglycemia in type 1 diabetes-a systematic review with GRADE. Diabetes Metab Res Rev. 2018;34(3). https:// doi.org/10.1002/dmrr.2965.

84. Baliunas DO, Taylor BJ, Irving H, Roerecke M, Patra J, Mohapatra S, et al. Alcohol as a risk factor for type 2 diabetes: a systematic review and metaanalysis. Diabetes Care. 2009;32(11):2123-32.

85. Polsky S, Akturk HK. Alcohol consumption, diabetes risk, and cardiovascular disease within diabetes. Curr Diab Rep. 2017;17(12):136.

86. Ahmed AT, Karter AJ, Liu J. Alcohol consumption is inversely associated with adherence to diabetes self-care behaviours. Diabet Med. 2006;23(7): 795-802.

87. Association AD. Nutrition recommendations and interventions for diabetes A position statement of the American Diabetes Association. Diabetes Care. 2008;31(Supplement 1):S61-78

88. Guo Y, Huang Z, Sang D, Gao Q, Li Q. The role of nutrition in the prevention and intervention of type 2 diabetes. Front Bioeng Biotechnol. 2020;8:575442

89. Khatib O. Noncommunicable diseases: risk factors and regional strategies for prevention and care; 2004.
90. Panagiotakos DB, Tzima N, Pitsavos C, Chrysohoou C, Papakonstantinou E, Zampelas A, et al. The relationship between dietary habits, blood glucose and insulin levels among people without cardiovascular disease and type 2 diabetes; the ATTICA study. Rev Diabet Stud. 2005;2(4):208-15.

91. Papamichou D, Panagiotakos DB, Itsiopoulos C. Dietary patterns and management of type 2 diabetes: a systematic review of randomised clinical trials. Nutr Metab Cardiovasc Dis. 2019;29(6):531-43.

92. Schauer PR, Bhatt DL, Kirwan JP, Wolski K, Aminian A, Brethauer SA, et al. Bariatric surgery versus intensive medical therapy for diabetes - 5-year outcomes. N Engl J Med. 2017;376(7):641-51.

93. Schauer PR, Bhatt DL, Kirwan JP, Wolski K, Brethauer SA, Navaneethan SD, et al. Bariatric surgery versus intensive medical therapy for diabetes--3-year outcomes. N Engl J Med. 2014;370(21):2002-13.

94. Khorgami Z, Shoar S, Saber AA, Howard CA, Danaei G, Sclabas GM. Outcomes of bariatric surgery versus medical management for type 2 diabetes mellitus: a meta-analysis of randomized controlled trials. Obes Surg. 2019;29(3):964-74.

95. Sharples AJ, Mahawar K. Systematic review and meta-analysis of randomised controlled trials comparing long-term outcomes of Roux-en-Y gastric bypass and sleeve gastrectomy. Obes Surg. 2020;30(2):664-72.

96. Mingrone G, Panunzi S, De Gaetano A, Guidone C, laconelli A, Capristo E, et al. Metabolic surgery versus conventional medical therapy in patients with type 2 diabetes: 10-year follow-up of an open-label, single-centre, randomised controlled trial. Lancet. 2021;397(10271):293-304.

97. Sjöström L, Peltonen M, Jacobson P, Ahlin S, Andersson-Assarsson J, Anveden $\AA$, et al. Association of bariatric surgery with long-term remission of type 2 diabetes and with microvascular and macrovascular complications. Jama. 2014;311(22):2297-304.

98. The Fifth IFSO Global registry report 2019. Available from: . https://www.ifso. com/pdf/5th-ifso-global-registry-report-september-2019.pdf.

99. Panunzi S, De Gaetano A, Carnicelli A, Mingrone G. Predictors of remission of diabetes mellitus in severely obese individuals undergoing bariatric surgery: do BMl or procedure choice matter? A meta-analysis. Ann Surg. 2015;261(3):459-67.

100. Angrisani L, Santonicola A, lovino P, Vitiello A, Higa K, Himpens J, et al. IFSO worldwide survey 2016: primary, endoluminal, and revisional procedures. Obes Surg. 2018;28(12):3783-94.

101. Buchwald H, Oien DM. Metabolic/bariatric surgery worldwide 2011. Obes Surg. 2013;23(4):427-36.

102. Buchwald $H$, Estok $R$, Fahrbach $K$, Banel $D$, Jensen MD, Pories WJ, et al. Weight and type 2 diabetes after bariatric surgery: systematic review and meta-analysis. Am J Med. 2009;122(3):248-56 e5.

103. Peterli R, Wölnerhanssen B, Peters T, Devaux N, Kern B, Christoffel-Courtin C, et al. Improvement in glucose metabolism after bariatric surgery: comparison of laparoscopic Roux-en-Y gastric bypass and laparoscopic sleeve gastrectomy: a prospective randomized trial. Ann Surg. 2009;250(2): 234-41.

104. Laferrère B, Teixeira J, McGinty J, Tran H, Egger JR, Colarusso A, et al. Effect of weight loss by gastric bypass surgery versus hypocaloric diet on glucose and incretin levels in patients with type 2 diabetes. J Clin Endocrinol Metab. 2008;93(7):2479-85.

105. Disse E, Pasquer A, Espalieu P, Poncet G, Gouillat C, Robert M. Greater weight loss with the omega loop bypass compared to the Roux-en-Y gastric bypass: a comparative study. Obes Surg. 2014;24(6):841-6.

106. Sánchez-Pernaute A, Herrera MA, Pérez-Aguirre ME, Talavera P, Cabrerizo L, Matía $P$, et al. Single anastomosis duodeno-ileal bypass with sleeve gastrectomy (SADI-S). One to three-year follow-up. Obes Surg. 2010;20(12): 1720-6.

107. Arble DM, Evers SS, Bozadjieva N, Frikke-Schmidt H, Myronovych A, Lewis A, et al. Metabolic comparison of one-anastomosis gastric bypass, singleanastomosis duodenal-switch, Roux-en-Y gastric bypass, and vertical sleeve gastrectomy in rat. Surg Obes Relat Dis. 2018;14(12):1857-67.

108. Rubino F, Schauer PR, Kaplan LM, Cummings DE. Metabolic surgery to treat type 2 diabetes: clinical outcomes and mechanisms of action. Annu Rev Med. 2010;61:393-411.

109. Heneghan HM, Nissen S, Schauer PR. Gastrointestinal surgery for obesity and diabetes: weight loss and control of hyperglycemia. Curr Atheroscler Rep. 2012;14(6):579-87.

110. Seetharamaiah S, Tantia O, Goyal G, Chaudhuri T, Khanna S, Singh JP, et al. LSG vs OAGB-1 year follow-up data-a randomized control trial. Obes Surg. 2017;27(4):948-54 
111. Lee WJ, Ser KH, Lee YC, Tsou JJ, Chen SC, Chen JC. Laparoscopic Roux-en-Y vs. mini-gastric bypass for the treatment of morbid obesity: a 10-year experience. Obes Surg. 2012;22(12):1827-34.

112. Lee WJ, Lee KT, Kasama K, Seiki Y, Ser KH, Chun SC, et al. Laparoscopic single-anastomosis duodenal-jejunal bypass with sleeve gastrectomy (SADJB-SG): short-term result and comparison with gastric bypass. Obes Surg. 2014;24(1):109-13.

113. Lee WJ, Chong K, Lin YH, Wei JH, Chen SC. Laparoscopic sleeve gastrectomy versus single anastomosis (mini-) gastric bypass for the treatment of type 2 diabetes mellitus: 5-year results of a randomized trial and study of incretin effect. Obes Surg. 2014;24(9):1552-62.

114. Adams TD, Gress RE, Smith SC, Halverson RC, Simper SC, Rosamond WD, et al. Long-term mortality after gastric bypass surgery. N Engl J Med. 2007; 357(8):753-61.

115. Caiazzo R, Arnalsteen L, Pigeyre M, Dezfoulian G, Verkindt H, Kirkby-Bott J, et al. Long-term metabolic outcome and quality of life after laparoscopic adjustable gastric banding in obese patients with type 2 diabetes mellitus or impaired fasting glucose. Br J Surg. 2010;97(6):884-91.

116. Dixon JB, O'Brien PE, Playfair J, Chapman L, Schachter LM, Skinner S, et al. Adjustable gastric banding and conventional therapy for type 2 diabetes: a randomized controlled trial. Jama. 2008;299(3):316-23.

117. Sultan S, Gupta D, Parikh M, Youn H, Kurian M, Fielding G, et al. Five-year outcomes of patients with type 2 diabetes who underwent laparoscopic adjustable gastric banding. Surg Obes Relat Dis. 2010;6(4):373-6.

118. Standards of medical care in diabetes--2009. Diabetes Care. 2009;32(Suppl 1):S13-S61.

119. Pories WJ, Swanson MS, MacDonald KG, Long SB, Morris PG, Brown BM, et al. Who would have thought it? An operation proves to be the most effective therapy for adult-onset diabetes mellitus. Ann Surg. 1995;222(3): 339-50; discussion 50-2.

120. Schauer PR, Burguera B, Ikramuddin S, Cottam D, Gourash W, Hamad G, et al. Effect of laparoscopic Roux-en $Y$ gastric bypass on type 2 diabetes mellitus. Ann Surg. 2003;238(4):467-84; discussion 84-5.

121. Sjöström L, Lindroos AK, Peltonen M, Torgerson J, Bouchard C, Carlsson B, et al. Lifestyle, diabetes, and cardiovascular risk factors 10 years after bariatric surgery. N Engl J Med. 2004;351(26):2683-93.

122. Gill RS, Birch DW, Shi X, Sharma AM, Karmali S. Sleeve gastrectomy and type 2 diabetes mellitus: a systematic review. Surg Obes Relat Dis. 2010; 6(6):707-13.

123. Vidal J, Ibarzabal A, Romero F, Delgado S, Momblán D, Flores L, et al. Type 2 diabetes mellitus and the metabolic syndrome following sleeve gastrectomy in severely obese subjects. Obes Surg. 2008;18(9):1077-82.

124. Bruno G, Gruden G, Barutta F, Cavallo Perin P, Morino M, Toppino M. What is the impact of sleeve gastrectomy and gastric bypass on metabolic control of diabetes? A clinic-based cohort of Mediterranean diabetic patients. Surg Obes Relat Dis. 2015;11(5):1014-9.

125. Parmar CD, Mahawar KK. One anastomosis (Mini) gastric bypass is now an established bariatric procedure: a systematic review of 12,807 patients. Obes Surg. 2018;28(9):2956-67.

126. Quan Y, Huang A, Ye M, Xu M, Zhuang B, Zhang P, et al. Efficacy of laparoscopic mini gastric bypass for obesity and type 2 Diabetes mellitus: a systematic review and meta-analysis. Gastroenterol Res Pract. 2015;2015: 152852.

127. Robert M, Espalieu P, Pelascini E, Caiazzo R, Sterkers A, Khamphommala L, et al. Efficacy and safety of one anastomosis gastric bypass versus Roux-enY gastric bypass for obesity (YOMEGA): a multicentre, randomised, openlabel, non-inferiority trial. Lancet. 2019;393(10178):1299-309.

128. Buchwald $H$. The evolution of metabolic/bariatric surgery. Obes Surg. 2014; 24(8):1126-35

129. Miras AD, le Roux CW. Mechanisms underlying weight loss after bariatric surgery. Nat Rev Gastroenterol Hepatol. 2013;10(10):575-84.

130. Cummings DE, Cohen RV. Bariatric/metabolic surgery to treat type 2 diabetes in patients with a BMI $<35$ kg/m2. Diabetes Care. 2016;39(6): 924-33.

131. Gloy VL, Briel M, Bhatt DL, Kashyap SR, Schauer PR, Mingrone G, et al. Bariatric surgery versus non-surgical treatment for obesity: a systematic review and meta-analysis of randomised controlled trials. BMJ. 2013;347: f5934.

132. Rubino F, Marescaux J. Effect of duodenal-jejunal exclusion in a non-obese animal model of type 2 diabetes: a new perspective for an old disease. Ann Surg. 2004;239(1):1-11.
133. le Roux CW, Aylwin SJ, Batterham RL, Borg CM, Coyle F, Prasad V, et al. Gut hormone profiles following bariatric surgery favor an anorectic state, facilitate weight loss, and improve metabolic parameters. Ann Surg. 2006; 243(1):108-14.

134. Manning S, Pucci A, Batterham RL. GLP-1: a mediator of the beneficial metabolic effects of bariatric surgery? Physiology. 2015;30(1):50-62.

135. Bose M, Olivan B, Teixeira J, Pi-Sunyer FX, Laferrere B. Do Incretins play a role in the remission of type 2 diabetes after gastric bypass surgery: what are the evidence? Obes Surg. 2009;19(2):217-29.

136. Prasad-Reddy L, Isaacs D. A clinical review of GLP-1 receptor agonists: efficacy and safety in diabetes and beyond. Drugs Context. 2015:4:212283.

137. Wang T, Gou Z, Wang F, Ma M, Zhai SD. Comparison of GLP-1 analogues versus sitagliptin in the management of type 2 diabetes: systematic review and meta-analysis of head-to-head studies. PLoS One. 2014;9(8):e103798.

138. Sanches E, Timmermans M, Topal B, Celik A, Sundbom M, Ribeiro R, et al. Cardiac remodeling in obesity and after bariatric and metabolic surgery; is there a role for gastrointestinal hormones? Expert Rev Cardiovasc Ther. 2019;17(11):771-90.

\section{Publisher's Note}

Springer Nature remains neutral with regard to jurisdictional claims in published maps and institutional affiliations.
Ready to submit your research? Choose BMC and benefit from:

- fast, convenient online submission

- thorough peer review by experienced researchers in your field

- rapid publication on acceptance

- support for research data, including large and complex data types

- gold Open Access which fosters wider collaboration and increased citations

- maximum visibility for your research: over $100 \mathrm{M}$ website views per year

At BMC, research is always in progress.

Learn more biomedcentral.com/submissions 